\title{
MICROEMULSION AND MICROEMULSION BASED GEL OF ZALEPLON FOR TRANSDERMAL DELIVERY: PREPARATION, OPTIMIZATION, AND EVALUATION
}

\author{
MUHAMMAD NAEEM ${ }^{1 *}$, ZARQA NAWAZ ${ }^{2}$, TANIYA IQBAL $^{3}$, SAJJAD HUSSAIN $^{4}$, \\ MUHAMMAD YOUSUF ${ }^{5}$, JAWAD AHMAD KHAN ${ }^{6}$, HAFIZ ARFAT IDREES $^{7}$ and ATIF ALI ${ }^{8}$
}

${ }^{1}$ Department of Pharmacy, Shah Abdul Latif University, Khairpur, Sindh.

${ }^{2}$ Department of Chemistry, The Islamia University of Bahawalpur, Bahawalpur. ${ }^{3}$ Institute of Chemical Sciences, Bahauddin Zakariya University, Multan

${ }^{4}$ Department of Zoology, University of Agriculture, Faisalabad

${ }^{5}$ Institute of Pharmaceutical Sciences, People University of Medical and Health Sciences for Women, Nawabshah

${ }^{6}$ Department of Pharmacy, Shah Abdul Latif University, Khairpur, Sindh

${ }^{7}$ Department of Pharmacy, The Islamia University of Bahawalpur, Bahawalpur ${ }^{8}$ Department of Pharmacy, COMSATS University Islamabad, Abbottabad Campus, Abbottabad

\begin{abstract}
In this work solubility and permeability of BCS II drug Zaleplon was increased by loading it into microemulsion which in turns enhance bioavailability. Carbomer 940 was incorporated to fabricate microemulsion based gel (MEBG) which sustained transdermal delivery. Solubility studies screened Castor oil, Tween 80 (surfactant), and Polyethylene glycol 200 (co-surfactant) for preparing Microemulsion. Pseudoternary phase diagrams were constructed to determine the microemulsion region. Box Behnken Design (BBD) was employed for optimizing microemulsions which were initially investigation for physicochemical characteristics. Oil, $\mathrm{S}_{\text {mix }}$ and water; $\mathrm{Q}_{24}$, Flux and lag time were selected as independent and dependent variables, respectively. Franz diffusion cell was employed to compare in vitro permeability for optimized microemulsions across Rabbit skin. Variables were related using mathematical equations and response surface plots. MEBG was distinguished for stability, in-vitro Zaleplon permeation, anti-inflammatory studies and skin irritation than control gel and in-vivo studies for oral tablet. Microemulsions showed $\mathrm{pH}$ of 5.36-5.98 (physiological), conductivity of 140-186 $\mu \mathrm{S} / \mathrm{cm}$, isotropic value of 1.340-1.417, average droplet size of 63-89 nm, homogeneity, droplet size of 53-61 $\mathrm{cP}$ and spherical shape. Predicted values of optimized microemulsions were found in reasonable agreement for experimental values. Preparations were stable and found to be skin non-irritant. When comparing edema percent inhibition of MEBG (85\%) and control gel (42\%) than standard, a significant difference was estimated. MEBG pattern differed significantly than oral tablet formulation for in vivo studies. This BBD based evaluation will decrease cost and time for designing drug, delivery and targeting.
\end{abstract}

Keywords: microemulsion components, MEBG, Box Behnchen design, physicochemical properties, in vitro studies, anti-inflammatory studies, in vivo studies

Zaleplon (pyrazolopyrimidine hypnotic drug) prescribed for the management of short term insomnia (1-2). It exhibits ideal characteristics like having low molecular weight of 305.54, ideal logarithmic partition coefficient of log octanol/water: 1.23, little dose of $1 \mathrm{mg}$ to $10 \mathrm{mg}$, poor oral bioavailability of $30.6 \pm 10.2 \%$, and half-life of $1.05 \pm 0.13 \mathrm{~h}$ for preparing transdermal delivery (3).

Despite, the drug comes across broad first-pass hepatic metabolism following oral absorption which results in only $30 \%$ bioavailability (4). Additionally, Zaleplon shows very little water solubility which owes to absorption is found to be dissolution rate-limited that concludes delayed and sustained onset of action (5-6).

This dispute can be resolved by using microemulsion, a successful vehicle that potentially and optimally increases drug solubility and permeation on skin. BCS II is an appropriate class of drugs formulated in microemulsion to enhance drug solubility and permeability (7-9).

\footnotetext{
* Corresponding author: e-mail: naeem_pk4@yahoo.com
} 

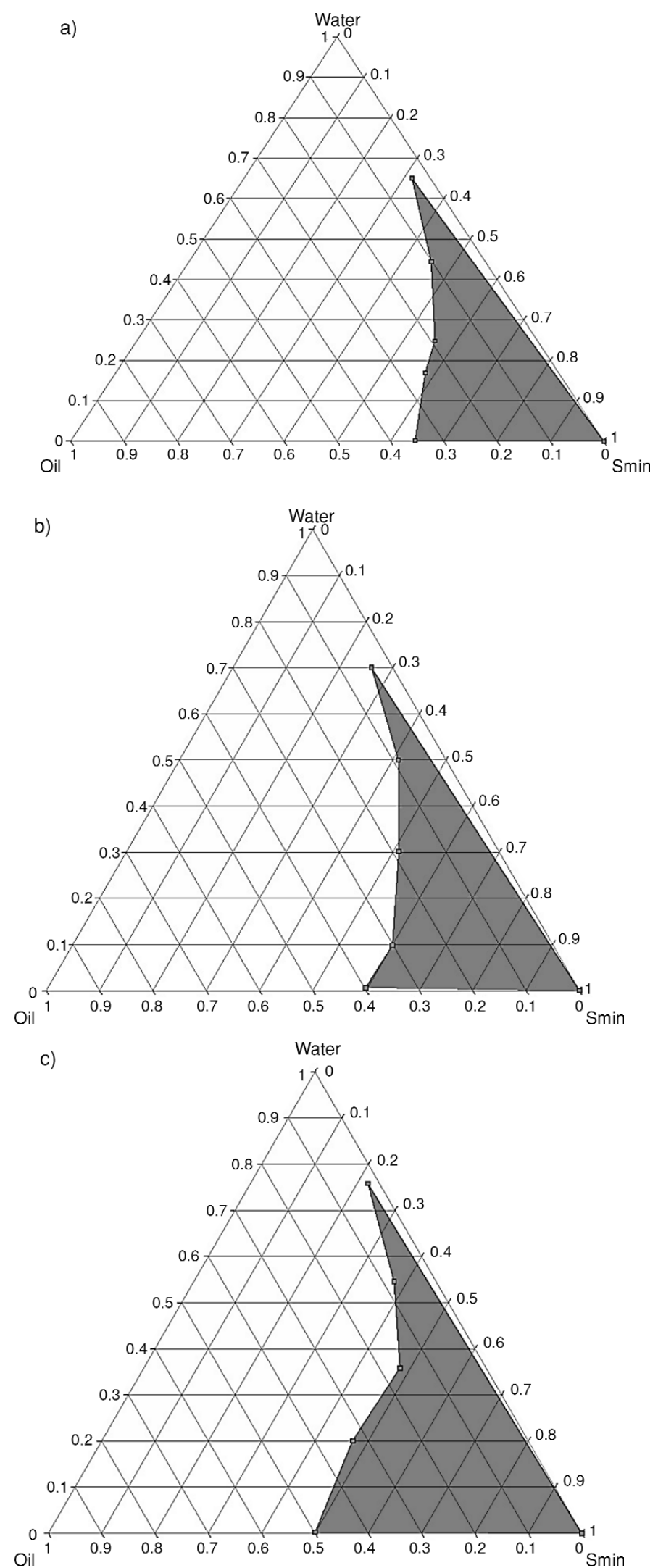

Figure 1. Pseudoternary phase diagrams of microemulsions using Smix at weight ratio a) $1: 1$ b) $2: 1$ and c) $3: 1$ 
It is an optimal vehicle to both dermal and transdermal delivery of drugs. There were various mechanisms suggested for exploring microemulsion significance to dermal and transdermal delivery (10). First, there is an incorporation of large amounts of drug into the microemulsion, which then increases the thermodynamics activity towards the skin. Second, there is skin partitioning owes to enhanced drug thermodynamic activity. Third, there is a reduction in stratum corneum diffusion barrier and increase of drug permeation rate across skin owing to microemulsion components which act as permeation enhancers (11).

BBD (Response Surface Methodology) is employed to optimize independent variables for estimating dependent variables for creation of polynomial equations using $1^{\text {st }}, 2^{\text {nd }}$ and quadratic models (12). It requires minimum experimentation and time than required for developing conventional dosage forms. It has dependent $\left(\mathrm{Q}_{24}\right.$, flux and lag time $)$ and independent (oil, Smix and water) variables.

In the current study, a new oil/water MEBG was fabricated successfully for transdermal delivery of Zaleplon to improve bioavailability by overcoming the problems of solubility, oral gastric toxicity, and permeability. BBD was used to optimize independent variables for estimating dependent variables. The formulations were characterized for $\mathrm{pH}$, viscosity, conductivity, refractive index, stability, skin irritation, anti-inflammatory, atomic force microscopy (AFM), zeta potential and size. Further, optimized formulations were distinguished for in vitro drug permeation and in vivo studies (bioavailability) than control.

\section{EXPERIMENTAL}

\section{Materials}

Zaleplon was gifted from Pfizer, Pakistan. Soybean oil, Castor oil, sesame oil, sunflower oil, peanut oil, isopropyl myristate, castor oil, almond oil, olive oil, eucalyptus oil, oleic acid, nutmeg oil, coconut oil, propylene glycol, tween 20, isopropanol, tween 80 and ethanol were purchased from Merck, Germany.

\section{Screening of components for microemulsions}

Microemulsion screening components was performed using $100 \mathrm{mg}$ of Zaleplon into $6 \mathrm{~mL}$ of individual surfactants, water, oils, and co-surfactants separately. The solubility of the drug in Phosphate buffer solution ( $\mathrm{pH}$ 7.4) was also investigated. Hot plate magnetic stirrer (VelpScienifca, Germany) was used to agitate the mixture for $72 \mathrm{~h}$ at ambient temperature. Then centrifugation (Centrifuge Machine, Hettich, Germany) was carried out for each mixture at 12000 RPM for 12 min and filtered using cellulose acetate membrane filter (Sartorius, Germany) of $0.45 \mu \mathrm{m}$ to obtain a supernatant. The amount of Zaleplon solubilized was measured at $374 \mathrm{~nm}$ with UV spectrophotometer (IRMECO $\mathrm{GmbH}$, Germany). The concentration of Zaleplon was measured from the calibration curve formed by using a linear regression equation $\left(\mathrm{R}^{2}=0.999\right)$.

$$
\mathrm{y}=0.047 \mathrm{x}+0.004
$$

where, (y is absorbance), $(\mathrm{x}=$ concentration $), 0.047$ is a slope $(\mathrm{m})$ and 0.004 is intercept $(\mathrm{c})$.

\section{Construction of pseudoternary phase diagram for microemulsions}

Pseudoternary phase diagrams of screened components (castor oil, water, polyethylene glycol 200 and tween 20) were prepared by water-based titration method for obtaining constituents concentration range for microemulsion existing range (13). Surfactant to co-surfactant weight ratios assorted like $1: 1,2: 1,3: 1,1: 2$ and $1: 3$. For individual diagram, at fixed $\mathrm{S}_{\text {mix }}$ weight ratios was added into oil at ratio of $1: 9,1: 8,1: 7,1: 6,1: 5,1: 4,1: 3.5$, $1: 3,1: 2.33,1: 2,1: 1.5,1: 1,1: 0.67,1: 0.43$, $1: 0.2$ and $1: 0.11$. Water was incorporated to individual oil and Smix, mixture at ambient temperature under magnetic stirring, prior to mixture became transparent and clear. The suitable concentrations of components were indexed and the pseudoternary phase diagrams were depicted in Figure 1. Oil, surfactant, co-surfactant, and water at optimal weight ratios were chosen based upon such results.

\section{Response surface methodology of microemulsions}

Response surface methodology (RSM) depends on statistical groups and mathematical strategies. It is employed for constructing an appropriate functional relationship for input and output variables. $1^{\text {st }}$ and $2^{\text {nd }}$ degree two model are explained using RSM. 1st order designs are found to be a simple design, Placket Burman and 2k factorial where $\mathrm{k}$ is control variables number. $3 \mathrm{k}$ factorial central composite and BBD is the most commonly used $2^{\text {nd }}$ order designs (12).

\section{Box Behnken Design of microemulsions}

$\mathrm{BBD}$ is used in industrial research. Independent variable concentrations were utilized at low $(-1)$ and high $(+1)$ levels for optimizing oil $\left(X_{1}\right)$, Smix $\left(\mathrm{X}_{2}\right)$ and water $\left(\mathrm{X}_{3}\right)$. It creates 17 possible microemulsion runs. $\mathrm{Q}_{24}\left(\mathrm{Y}_{1}\right)$, flux $\left(\mathrm{Y}_{2}\right)$ and lag time $\left(\mathrm{Y}_{3}\right)$ are three dependent variables (11). 


\section{Microemulsion preparation and PBS}

The microemulsion was prepared by a procedure as follows: Tween 80 (surfactant) and Polyethylene 200 (co-surfactant) were used to prepare Smix. After that castor oil was added to a mixture of Smix. Zaleplon at $0.250 \%$ concentration was dissolved to the oily mixture under Ultra-Sonication (Elma, Germany). Water was mixed drop by drop to oil mixture using moderate magnetic stirring at room temperature for preparing microemulsion oil/water.

Control prepared using the following procedure: In the first step, PBS having pH 7.4 was fabricated using $0.2 \mathrm{M}$ potassium dihydrogen phosphate and $0.2 \mathrm{M}$ sodium hydroxide solutions. In the $2^{\text {nd }}$ step, Zaleplon was mixed for preparing PBS of Zaleplon at ambient temperature under moderate magnetic stirring.

\section{MEBG fabrication and Zaleplon control gel}

Gel bases of Carbomer 940 were prepared at $0.50 \%, 0.75 \%$ and $1.00 \%$ separately concentrations using distilled water. Afterward, the dispersion was preserved over-night in order to polymer swelling into a gel network. Triethylamine (TEA) was mixed in drops until a semisolid consistency gel-like was achieved. pH was 6-8 at gel consistency stage. Therefore, optimized Zaleplon microemulsion was slowly mixed with Carbomer $9400.75 \%$ gel base under magnetic stirring (5). Control gel was also fabricated by adding Zaleplon PBS into gel base of $0.75 \%$.

\section{Characterization}

$\mathrm{pH}$ measurement was carried out by $\mathrm{pH}$ meter (WTW inoLab, Germany).Viscosities of microemulsions were determined at $25^{\circ} \mathrm{C}$ using Brookfield RVDV III ultra, Programmable Rheometer (Brookfield Engineering Laboratories, Middleboro, MA). Conductivities $(\sigma)$ was determined by Conductometer (197i Weilhein, WTW Cond, Germany). Refractive index was determined using BallinghamStanely (RFM 330 plus). The droplet size and polydispersity index of optimized microemulsion was analyzed for dynamic light scattering employed a Zeta sizer (Malvern Nano-ZS, UK). Microemulsions surface morphology and shape was evaluated using atomic force microscopy (AFM, XE-100, PSIA, Korea). The analysis was conducted in triplicate.

\section{Permeation study \\ Preparation of skin}

Approval for this study was taken from the Advanced Study and Research Board (ASARB), The Islamia University of Bahawalpur Pakistan. A male Rabbit weighing approximately $2.5 \mathrm{~kg}$ was used to take skin for permeation studies. Hairs were carefully trimmed with an electric clipper from the dorsal region of the Rabbit. The Rabbit was sacrificed and skin was isolated at the dorsal region. Heat separation technique (14) was used to prepare epidermis. The skin was soaked in pH 7.4 PBS for 45 $\mathrm{sec}$ at $60^{\circ} \mathrm{C}$ to extract adhered tissue. Then, the skin was washed with water, excised in surface area of $1.767 \mathrm{~cm}^{2}$ and used for permeation in vitro studies.

\section{In vitro permeation study microemulsions}

The transport of the drug across the skin is challenging and critical process in the area of both dermal and transdermal delivery. Franz diffusion cell (PermeGear, USA) has surface area of 1.767 $\mathrm{cm}^{2}$. It consists of donor and receiver compartments (13). Excised skin was fixed tightly in between two compartments using stratum corneum towards the upper side of donor compartment. Donor compartment was loaded with $4 \mathrm{~g}$ ME (10 mg Zaleplon) and covered with aluminum foil to prevent evaporation. Receiver compartment (12 mL volume capacity) was filled with pH 7.4 PBS and 5\% propylene glycol (PG) to maintain sinks conditions. It was degassed to prevent any bubble formation. It also contained Teflon coated magnetic stirrer to agitate contents of the receiver compartment on hot plate magnetic stirrer. Receiver compartment temperature was maintained at $37 \pm 0.5^{\circ} \mathrm{C}$ using water bath and peristaltic pump was used as a mechanical pump with which pressure is created by the movement of a constriction along the tube, likewise to biological peristalsis. Sampling was performed at fixed time intervals $(0,1,2,3,4,5,6,8$, $10,12,14,16,20$, and $24 \mathrm{~h}$ ) from receiver compartment. The lost quantity was replenished with an equal quantity of PBS and 5\% PG. Diluted samples were analyzed using UV spectrophotometer (IRMECO $\mathrm{GmbH}$, Germany) at $374 \mathrm{~nm}$.

\section{Permeation data analysis}

Zaleplon cumulative amount permeated $\left(\mathrm{Q}_{24}\right)$ was determined and concentrations corrected of sampling effects using following relation (11):

$$
\mathrm{C}_{\mathrm{n}}^{1}=\mathrm{C}_{\mathrm{n}}\left(\mathrm{V}_{\mathrm{T}} / \mathrm{V}_{\mathrm{T}}-\mathrm{V}_{\mathrm{S}}\right)\left(\mathrm{C}_{\mathrm{n}-1}^{1} / \mathrm{C}_{\mathrm{n}-1}\right)
$$

$\mathrm{C}_{\mathrm{n}}{ }_{\mathrm{n}}$ and $\mathrm{C}_{\mathrm{n}}$ are found to be corrected and determined concentrations of Zaleplon at $\mathrm{n}^{\text {th }}$ sample, respectively. $\mathrm{C}_{\mathrm{n}-1}^{1}$ is the determined Zaleplon concentration in the $(\mathrm{n}-1)^{\text {th }}$ sample, $\mathrm{V}_{\mathrm{T}}$ and $\mathrm{V}_{\mathrm{S}}$ are receiver fluid volume and extracted sample, respectively.

Permeation profile was calculated by plotting graph between $\mathrm{Q}_{24}$ and time. Linear regression analysis was used as a tool for calculating steadystate flux $\left(J_{s s}, \mu g / \mathrm{cm}^{2} / \mathrm{hr}\right)$ of Zaleplon. Lag time was 
measured in the plot between $\mathrm{Q}_{24}(\mathrm{Y}$-axis) and time (X-axis) using intercept on time axis.

Permeability coefficient $\left(\mathrm{K}_{\mathrm{p}}\right)$ was measured through the ratio of flux over drug concentration in the microemulsion. Enhancement ratio (Er) was determined as the ratio of microemulsion flux andcontrol flux(15).

\section{Experimental design \\ Independent and dependent variables}

Franz diffusion cell was employed for performing in vitro permeation studies for 17 microemulsions runs for calculating dependent variables values. BBD was employed to analyze main effects, quadratic effects and interaction effects over dependent variables. DES was applied for constructing $1^{\text {st }}, 2^{\text {nd }}$ and quadratic models. DES was particularly chosen as it requires fewer runs as compared to central composite design (CCD) for the case of 3 or 4 variables. Such cubic design was compared to a set of points present in the midpoint of every edge and multi-dimensional cube central points. DES was employed to produce nonlinear quadratic model equation and represented as: $\left(Y=b_{0}+b_{1} X_{1}+b_{2} X_{2}\right.$ $+b_{3} X_{3}+b_{12} X_{1} X_{2}+b_{13} X_{1} X_{3}+b_{23} X_{2} X_{3}+b_{11} X_{1}^{2}$ $+b_{22} X_{2}^{2}+b_{33} X_{3}^{2}$ ).

\section{Checkpoint analysis and optimization model val- idation of microemulsion \\ SPSS software was applied for statistically val- idating polynomial equations by ANOVA. $\mathrm{R}^{2}$, adjusted $\mathrm{R}^{2}$, predicted $\mathrm{R}^{2}$ and adequate precision were analyzed. Optimum parameters are found by conducting feasibility and grid searches. 3D RSP were generated using DES. Ten optimum check- point preparations were utilized for validating poly- nomial equations and experimental models over the whole experimental region through intensive grid search. Ten checkpoint formulations response prop- erties were estimated for each factor. Percentage prediction error was generated by comparing exper- imental and predicted values.}

\section{Stability study}

Optimized $\mathrm{ME}_{1}$ and MEBG stability studies were conducted. Centrifugation (Hettich, Germany) was performed for $30 \mathrm{~min}$ at $3500 \mathrm{rpm}$. Ultra-low temperature freezer (Sanyo, Japan) was performed to determine three freeze-thaw cycles. Preparations were also kept at $40 \pm 2^{\circ} \mathrm{C} / 75 \pm 5 \% \mathrm{RH}$ (Relative Humidity) for a period of six months in amber colored containers. Sampling was conducted at fixed time intervals 1, 2, 3 and 6 months. Preparations were inspected for visual clarity, transparency, phase separation, color change, non-grittiness and drug content (16).

\section{Skin irritation study of MEBG}

Mexameter (from Courage and Khazaka Electronic GmbH, Cologne, Germany) was employed to quantify erythema of the skin. Skin irritation study was conducted using six Rabbits. The hairs were trimmed with electrical shaver from the dorsal side. Stretch adhesive tapes (Paragon $^{\mathrm{TM}}$ ) are employed for application of MEBG and investigated for erythema development for one week (17).

\section{Anti-inflammatory study}

Rabbits were used for performing the antiinflammatory study by making their three groups, with each group consisted of six Rabbits. Group I was selected as standard without treatment. Zaleplon MEBG and control gel was applied to dorsal Rabbit skin available in group II and III, separately. Formalin, as standard irritant was applied 1 hour before MEBG and control gel application. 7 days employed for experimentation for all three groups. Zaleplon MEBG and control gel were applied once a day for 7 days and the application area was determined using Vernier Caliper for edema appearance and disappearance (18). For obtaining constant results the calculations and observations were triplicately recorded.

\section{In vivo evaluation}

24 Rabbits were selected and shifted to 2 groups (12 each). Commercial Sonata capsules were provided to Rabbits using a syringe to make easy the capsules in suspension form administration; reducing retention time in mouth and rebuff ultimately. It was distinguished with transdermal Zaleplon MEBG. This method used for application was according to explained skin Irritation study. Despite, for in vivo estimation, single dose was provided for $48 \mathrm{~h}$ and then blood samples were extracted out for examining Zaleplon. The vacuum tube was employed for collecting blood samples to analyze at specific fixed time intervals containing anti-coagulant (Vacutainer, BD) sodium heparin. Blood samples were extracted through indwelling cannula from Rabbits marginal ear vein after MEBG and oral tablet formulations delivery. Samples of blood were centrifuged for $15 \mathrm{~min}$ at $3500 \mathrm{rpm}$. Plasma was shifted to a new centrifuge tube and then frozen at $-20^{\circ} \mathrm{C}$ before further investigation. Per-chloric acid solution $(100 \mu \mathrm{L})$ was added with $1 \mathrm{~mL}$ of plasma samples for precipitating proteins. Screened mixtures were vortexed at 3000 RPM for $2 \mathrm{~min}$, then 
again centrifuged for $10 \mathrm{~min}$. The supernatant was transferred to Eppendorf $2 \mathrm{~mL}$ microcentrifuge tube. Clear and transparent supernatant was preserved under the flux of nitrogen for concentrating supernatant and mixed with the mobile phase. Its $10 \mu \mathrm{L}$ was employed via reverse-phase HPLC (Waters alliance 2695 separation module with water 486 detectors) injection port for analyzing Zaleplon concentration present in serum. Limit of detection (LOD) and Limit of quantification (LOQ) were 5 $\mathrm{ng} / \mathrm{mL}$ and $10 \mathrm{ng} / \mathrm{mL}$, respectively. Plasma samples of Zaleplon were investigated for previously constructed HPLC method (19). Briefly, HPLC system was equipped to binary pump solvent transporting system, using reverse phase C-18 (Discovery® HS, $15 \mathrm{~cm} 4.6 \mathrm{~mm}, 5 \mu \mathrm{m})$ stainless steel analytical column. Samples chromatographic peaks were inscribed at $232 \mathrm{~nm}$ wavelength. Solvent system was first degaussed before utilization for sonicator (Elma D 78224, Germany).

The mobile phase consisted of methanol (50\%) and ammonium acetate buffer $(50 \%) \mathrm{v} / \mathrm{v}$ mixture.
Maintain pH at 3.2 using ortho-phosphoric acid. The mobile phase was filtered using $0.45 \mu \mathrm{m}$ diameter membranes (Sartorius, Germany) and then degassed before use for ultra-sonication. The flow rate was adjusted and fixed at $1 \mathrm{~mL} / \mathrm{min}$. Many pharmacokinetic parameters, as Cmax, Tmax and AUC were determined to estimate in vivo bioavailability studies. Zaleplon concentration was analyzed constructing a calibration curve that was modeled at the linear regression equation $\left(\mathrm{R}^{2}=0.993\right)$.

$$
y=13.07 x+0.517
$$

where $\mathrm{y}$ is Sample response ratio, $\mathrm{x}$ is the regression line slope, 13.07 is slope and 0.517 is regression line intercept with the y-axis.

\section{Statistical analysis}

One way analysis of variance (ANOVA) and Paired sample $t$-test was employed for statistical analysis at $\mathrm{p}<0.05$ as a significance minimal level. Values were recorded and investigated frequently for 3 times. Data was depicted as mean value \pm S.D.

Table 1. Solubility of Zaleplon in oils, surfactants and co-surfacatants, values presented are mean $+\mathrm{SD}(\mathrm{n}=3)$.

\begin{tabular}{|c|c|c|}
\hline & Components & Solubility $(\mathrm{mg} / \mathrm{mL})$ Mean \pm SD \\
\hline \multirow{11}{*}{ Oils } & Sesame oil & $30 \pm 0.55$ \\
\hline & Soybean oil & $45 \pm 0.60$ \\
\hline & Sunflower oil & $33 \pm 0.58$ \\
\hline & Oleic acid & $58 \pm 0.70$ \\
\hline & Labrafil M1944 & $55 \pm 0.68$ \\
\hline & Linoleic acid & $30 \pm 0.40$ \\
\hline & Labrafac & $65 \pm 0.70$ \\
\hline & Triacetin & $70 \pm 0.72$ \\
\hline & Peanut oil & $39 \pm 0.44$ \\
\hline & Isopropyl myristate & $90 \pm 0.88$ \\
\hline & Castor oil & $135 \pm 0.90$ \\
\hline \multirow{5}{*}{ Surfactants } & Cremophore RH40 & $70 \pm 0.55$ \\
\hline & Span 20 & $45 \pm 0.37$ \\
\hline & Span 80 & $57 \pm 0.66$ \\
\hline & Tween 20 & $75 \pm 0.56$ \\
\hline & Tween 80 & $80 \pm 0.37$ \\
\hline \multirow{6}{*}{ Co-surfactants } & Polyethylene 200 & $85 \pm 0.62$ \\
\hline & Polyethylene 400 & $60 \pm 0.57$ \\
\hline & Ethanol & $35 \pm 0.68$ \\
\hline & Propylene glycol & $65 \pm 0.72$ \\
\hline & Water & $0.0403 \pm 0.008$ \\
\hline & PBS (pH 7.4) & $5.9 \pm 0.025$ \\
\hline
\end{tabular}




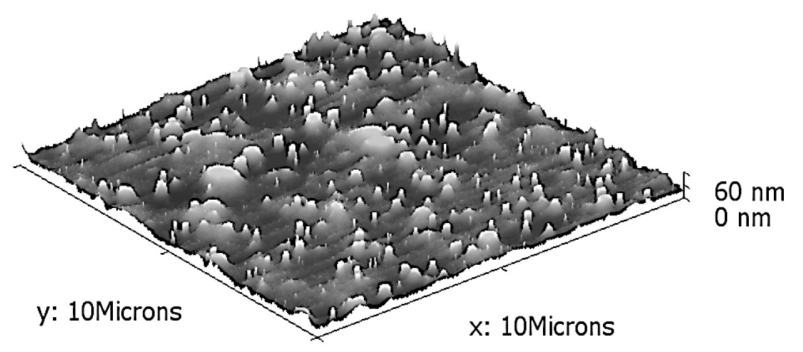

Figure 2. AFM image of Zaleplon microemulsion

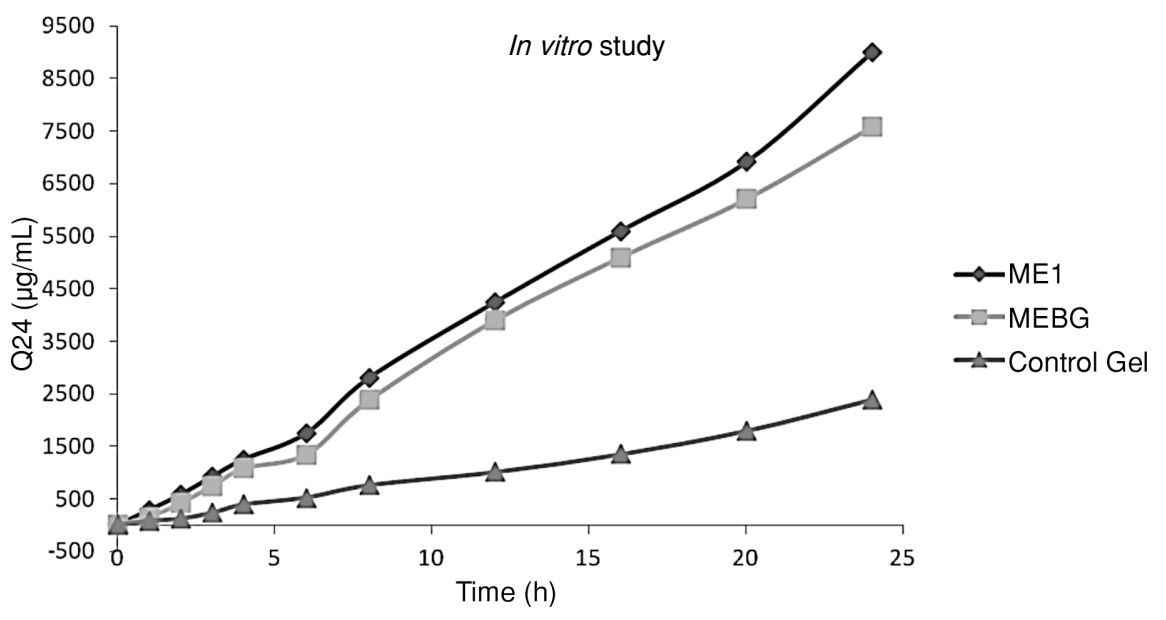

Figure 3. In vitro permeation profiles of Zaleplon( $\mathrm{ME}_{1}, \mathrm{MEBG}$ and control $)(\mathrm{n}=3)$

\section{RESULTS}

\section{Selection of components for microemulsions}

Solubility data are given in Table 1. Castor oil, tween 20, polyethylene 200 and water was selected as microemulsion components as these showed comparatively greater solubility and miscibility to other microemulsion components. Solubility values $(\mathrm{mg} / \mathrm{mL})$ of $135,80,85,0.0403$ and 5.9 were noticed castor oil, tween 80, polyethylene 200, water and PBS pH 7.4, respectively.

\section{Construction of pseudoternary phase diagrams}

Oil and Smix concentrations were dependent on water uptake into the microemulsion via trial and error method. Diagrams at weight ratios for Smix $1: 1,2: 1,3: 1$ are shown in Figure 1. Translucent microemulsion region was segregated using the shaded area. The turbid area was separated towards the left side. Smix using weight ratio $3: 1$ exhibited higher microemulsion region than with ratios $2: 1$ and $1: 1$. All preparations were isotropic, clear and thermo-dynamically stable. Diagram a weight ratio of $3: 1$ was chosen and mixed with Zaleplon.
Physicochemical characteristics of microemulsions

Values 5.36-5.99, 53-161cP, 1.340-1.417, $0.106-0.378,63-89 \mathrm{~nm}$ and $140-186 \mu \mathrm{S} / \mathrm{cm}$ were for $\mathrm{pH}$, viscosity, refractive index, polydispersity index, average droplet size, and conductivity of 17 runs were in the range of, respectively. $\mathrm{pH}$, viscosity, refractive index, polydispersity index and conductivity values of optimized $\mathrm{ME}_{1}$ were $5.46,53 \mathrm{cP}$, $1.386,0.106$ and $186 \mu \mathrm{S} / \mathrm{cm}$, respectively (Table 2). Optimized $\mathrm{ME}_{7}$ has droplet size of $63 \mathrm{~nm}$ measured with zeta sizer and AFM. AFM results showed in Figure 2. The zeta potential was $-0.149 \mathrm{mV}$ that was near to neutral.

\section{In vitro skin permeation Experiments}

A permeation study of 17 possible runs microemulsions, MEBG and control gel formulation was performed through Rabbit skin. Zaleplon permeation parameters $\left(Q_{24}\right.$, flux and lag time) were determined to all experimental microemulsions. $\mathrm{Q}_{24}$, flux and lag time values were 5899-9001 $\mu \mathrm{g}, 110$ $145 \mu \mathrm{g} / \mathrm{cm}^{2} / \mathrm{h}$ and $0.19-0.45 \mathrm{hr}$, respectively, for all 17 runs. Preparation $\mathrm{ME}_{7}$ exhibited maximum val- 
ues of $\mathrm{Q}_{24}(9001 \mu \mathrm{g})$ and flux $\left(145 \mu \mathrm{g} / \mathrm{cm}^{2} / \mathrm{h}\right)$ and; minimum value of lag time $(0.19 \mathrm{hr})$. MEBG exhibited $7570 \mu \mathrm{g}, 80 \mu \mathrm{g} / \mathrm{cm}^{2} / \mathrm{h}$ and $0.99 \mathrm{hr}$ values for $\mathrm{Q}_{24}$, flux and lag time, respectively. Control gel preparation determined values for $\mathrm{Q}_{24}$, flux and lag time were $1186 \mu \mathrm{g}, 35 \mu \mathrm{g} / \mathrm{cm}^{2} / \mathrm{h}$ and $1.4 \mathrm{hr}$, respectively.

Permeation mechanism was shown in Figure 3 of $\mathrm{ME}_{7}, \mathrm{MEBG}$ and control gel. Relative optimum Zaleplon microemulsion showed a significant decrease in $\mathrm{Q}_{24}$ when $\mathrm{ME}_{7}$ was mixed with Carbomer 940 gel base. Despite, lag time to fabricate MEBG was estimated at $0.99 \mathrm{hr}$ that was found to be significantly greater from $\mathrm{ME}_{7}$ lag time. Optimized $\mathrm{ME}_{7}$ enhancement ratio was 4.1 times higher as compared to control preparation. MEBG enhancement ratio was 2.3 times greater as compared to control formulation. $\mathrm{ME}_{7}, \mathrm{MEBG}$ and control gel formulations in vitro study are shown in Figure 3 that depicted permeation parameters widely affected using varying microemulsion composition.

\section{Formulation optimization}

Independent variables and responses are depicted in Table 3. Contour and response surface plots (3D) are shown in Figure 4. 4, 5, 6 were mathematical quadratic equations which were created using DES.
It explains significantly greater $\mathrm{Q}_{24}\left(\mathrm{Y}_{1}=7881\right.$ $-9001 \mu \mathrm{g})$ and flux $\left(\mathrm{Y}_{2}=118-145 \mu \mathrm{g} / \mathrm{cm}^{2} / \mathrm{h}\right)$ by using oil and Smix concentrations at -1 or 0 and 0 or +1 , respectively. When Smix at -1 to +1 was utilized, it exhibits $\mathrm{Q}_{24}$, flux and lag time in 5899-9001 $\mu \mathrm{g}, 110-145 \mu \mathrm{g} / \mathrm{cm}^{2} / \mathrm{h}, 0.19-0.45 \mathrm{hr}$ range, respectively. Higher drug permeation is determined using oil, Smix and water at low, medium and high levels, respectively. Lower drug permeation of oil, Smix and water was noticed at high, high and medium level, respectively. Preparation variables and levels with various ratios were employed to determine quantitative effects for $\mathrm{Q}_{24}$, flux and lag time. DES was employed to measure response surface plots via using the factor levels values. The model was demonstrated as:

$$
\begin{gathered}
\mathrm{Y}_{1}\left(\mathrm{Q}_{24}\right)=8560+1405 \mathrm{X}_{1}+387 \mathrm{X}_{2}+90 \mathrm{X}_{3}- \\
275 \mathrm{X}_{1} \mathrm{X}_{2}-37.25 \mathrm{X}_{1} \mathrm{X}_{3}-77.5 \mathrm{X}_{2} \mathrm{X}_{3}-535 \mathrm{X}_{1}^{2}- \\
201 \mathrm{X}_{2}^{2}+19 \mathrm{X}_{3}^{2} \\
\mathrm{Y}_{2}(\text { Flux })=126.2+13.13 \mathrm{X}_{1}-4.50 \mathrm{X}_{2}+ \\
0.62 \mathrm{X}_{3} \\
\mathrm{Y}_{3}(\text { Lagtime })=0.30-0.096 \mathrm{X}_{1}-0.040 \mathrm{X}_{2}- \\
1.25 \mathrm{X}_{3}
\end{gathered}
$$

\section{Thermodynamic stability study}

After visual notice, it is observed that optimized preparations were found out stable when undergoes freeze-thaw cycles and centrifugation.

Table 2. Characterization of microemulsions.

\begin{tabular}{|c|c|c|c|c|c|c|}
\hline Codes & $\mathrm{pH}$ & $\begin{array}{c}\text { Conductivity } \\
\sigma(\mu \mathrm{S} / \mathrm{cm})\end{array}$ & $\begin{array}{c}\text { Viscosity } \\
(\mathrm{cP})\end{array}$ & $\begin{array}{c}\text { Refractive } \\
\text { index }\end{array}$ & $\begin{array}{c}\text { Poly dispersity } \\
\text { index }\end{array}$ & $\begin{array}{c}\text { Average droplet } \\
\text { size(nm) }\end{array}$ \\
\hline $\mathrm{ME}_{1}$ & 5.46 & $186 \pm 3.1$ & $53 \pm 0.45$ & 1.386 & $0.106 \pm 0.021$ & 89 \\
\hline $\mathrm{ME}_{2}$ & 5.42 & $184 \pm 2.1$ & $56 \pm 0.34$ & 1.340 & $0.118 \pm 0.027$ & 85 \\
\hline $\mathrm{ME}_{3}$ & 5.96 & $141 \pm 1.4$ & $146 \pm 0.41$ & 1.404 & $0.343 \pm 0.016$ & 76 \\
\hline $\mathrm{ME}_{4}$ & 5.77 & $168 \pm 1.7$ & $100 \pm 0.98$ & 1.375 & $0.234 \pm 0.014$ & 79 \\
\hline $\mathrm{ME}_{5}$ & 5.75 & $166 \pm 2.9$ & $102 \pm 0.77$ & 1.376 & $0.242 \pm 0.015$ & 81 \\
\hline $\mathrm{ME}_{6}$ & 5.80 & $170 \pm 2.5$ & $98 \pm 0.80$ & 1.373 & $0.230 \pm 0.028$ & 69 \\
\hline $\mathrm{ME}_{7}$ & 5.36 & $176 \pm 3.5$ & $63 \pm 0.55$ & 1.346 & $0.142 \pm 0.010$ & 63 \\
\hline $\mathrm{ME}_{8}$ & 5.70 & $161 \pm 1.1$ & $111 \pm 0.63$ & 1.390 & $0.270 \pm 0.026$ & 75 \\
\hline $\mathrm{ME}_{9}$ & 5.74 & $165 \pm 2.6$ & $105 \pm 0.70$ & 1.378 & $0.247 \pm 0.024$ & 71 \\
\hline $\mathrm{ME}_{10}$ & 5.65 & $156 \pm 2.7$ & $108 \pm 0.61$ & 1.392 & $0.276 \pm 0.013$ & 73 \\
\hline $\mathrm{ME}_{11}$ & 5.98 & $150 \pm 2.8$ & $141 \pm 0.53$ & 1.403 & $0.334 \pm 0.011$ & 65 \\
\hline $\mathrm{ME}_{12}$ & 5.73 & $164 \pm 1.3$ & $108 \pm 0.67$ & 3.380 & $0.257 \pm 0.022$ & 78 \\
\hline $\mathrm{ME}_{13}$ & 5.93 & $146 \pm 1.6$ & $154 \pm 0.36$ & 1.411 & $0.358 \pm 0.020$ & 84 \\
\hline $\mathrm{ME}_{14}$ & 5.71 & $163 \pm 2.5$ & $109 \pm 0.65$ & 3.82 & $0.266 \pm 0.019$ & 87 \\
\hline $\mathrm{ME}_{15}$ & 5.90 & $140 \pm 3.5$ & $161 \pm 0.78$ & 1.417 & $0.378 \pm 0.017$ & 70 \\
\hline $\mathrm{ME}_{16}$ & 5.40 & $181 \pm 1.5$ & $61 \pm 0.50$ & 1.343 & $0.131 \pm 0.012$ & 88 \\
\hline $\mathrm{ME}_{17}$ & 5.84 & $172 \pm 1.3$ & $91 \pm 0.75$ & 1.371 & $0.216 \pm 0.023$ & 74 \\
\hline
\end{tabular}


Table 3. Variables and observed responses in Box Behnken design for microemulsions.

\begin{tabular}{|c|c|c|c|c|c|c|c|}
\hline \multirow[b]{2}{*}{ Microemulsion } & \multicolumn{3}{|c|}{ Independent variables } & \multicolumn{3}{|c|}{ Dependent variables } & \multirow[t]{2}{*}{ Enhancement ratio } \\
\hline & $\begin{array}{c}\text { Oil } \\
X_{1}(g)\end{array}$ & $\begin{array}{l}\text { Smix } \\
\mathrm{X}_{2}(\mathrm{~g})\end{array}$ & $\begin{array}{l}\text { Water } \\
\mathrm{X}_{3}(\mathrm{~g})\end{array}$ & $\begin{array}{c}\mathrm{Q}_{24} \\
\mathrm{Y}_{1}(\mu \mathrm{g})\end{array}$ & $\begin{array}{c}\text { Flux } \\
\mathrm{Y}_{2} \mu \mathrm{g} / \mathrm{cm}^{2} / \mathrm{h}\end{array}$ & $\begin{array}{c}\text { Lag Time } \mathrm{Y}_{3} \\
\text { (hour) }\end{array}$ & \\
\hline ME1 & -1 & 0 & +1 & 9001 & 145 & 0.19 & 4.14 \\
\hline ME2 & 0 & +1 & +1 & 7881 & 118 & 0.34 & 3.37 \\
\hline ME3 & 0 & +1 & -1 & 7945 & 120 & 0.34 & 3.43 \\
\hline ME4 & 0 & 0 & 0 & 8133 & 124 & 0.33 & 3.54 \\
\hline ME5 & 0 & 0 & 0 & 8233 & 126 & 0.31 & 3.60 \\
\hline ME6 & -1 & -1 & 0 & 8830 & 139 & 0.21 & 3.97 \\
\hline ME7 & +1 & 0 & +1 & 7222 & 117 & 0.36 & 3.34 \\
\hline ME8 & +1 & +1 & 0 & 5899 & 110 & 0.45 & 3.14 \\
\hline ME9 & 0 & 0 & 0 & 8230 & 126 & 0.31 & 3.60 \\
\hline ME10 & +1 & -1 & 0 & 6683 & 115 & 0.38 & 3.29 \\
\hline ME11 & -1 & 0 & -1 & 8950 & 142 & 0.20 & 4.06 \\
\hline ME12 & 0 & 0 & 0 & 8420 & 130 & 0.25 & 3.71 \\
\hline ME13 & 0 & -1 & -1 & 8061 & 122 & 0.34 & 3.49 \\
\hline ME14 & 0 & 0 & 0 & 8421 & 131 & 0.23 & 3.74 \\
\hline ME15 & +1 & 0 & -1 & 6313 & 114 & 0.39 & 3.26 \\
\hline ME16 & 0 & -1 & +1 & 8690 & 120 & 0.34 & 3.43 \\
\hline ME17 & -1 & +1 & 0 & 8741 & 135 & 0.21 & 3.86 \\
\hline \multirow{2}{*}{\multicolumn{2}{|c|}{ Independent variables }} & & \multicolumn{4}{|c|}{ Levels used, actual (coded) } & \\
\hline & & Low ( & & edium $(0)$ & High & $(+1)$ & \\
\hline \multicolumn{2}{|c|}{ Oil (g) } & \multicolumn{2}{|l|}{9} & 16.5 & \multicolumn{2}{|c|}{24} & \\
\hline \multicolumn{2}{|c|}{ Smix (g) } & \multicolumn{2}{|c|}{41} & 48.5 & \multicolumn{2}{|c|}{56} & \\
\hline \multicolumn{2}{|c|}{ Water $(\mathrm{g})$} & \multicolumn{2}{|c|}{28} & 39.5 & 5 & & \\
\hline
\end{tabular}

Optimized $\mathrm{ME}_{1}$ and MEBG showed the concentration of Zaleplon was $98.5 \%$ and $98.3 \%$, respectively, in samples during 6 months. Results revealed the drug Zaleplon found stable in this study. Optimized $\mathrm{ME}_{1}$ and MEBG exhibited $\mathrm{Q}_{24}$ values of $8867 \mu \mathrm{g}$ and $7441 \mu \mathrm{g}$, respectively, for drug Zaleplon released and permeated during $24 \mathrm{~h}$. Flux values were 143 and $78 \mu \mathrm{g} / \mathrm{cm}^{2} / \mathrm{h}$ for optimized $\mathrm{ME}_{1}$ and $\mathrm{MEBG}$, respectively. Results exhibit insignificant difference $(p>0.05)$ for permeation than initial permeation studies representing both preparations were stable. The insignificant change was noticed regarding visual clarity, drug content, transparency, color change, phase separation and non-grittiness.

\section{Skin irritation study}

It is an arbitrary unit determined using Mexameter. It showed values in the range of 210-270 and 221-280 before and after MEBG appli- cation, respectively. Insignificant change in erythema was noticed following MEBG application that showing MEBG as non-irritant.

\section{Anti-inflammatory study}

Edema instigated through Formalin model was employed for distinguishing Zaleplon MEBG antiinflammatory activity with conventional Zaleplon gel. A significant difference was measured after comparing MEBG (85\%) edema percent inhibition than control gel (44\%) with regard to without using gel (standard) (Figure 5).

\section{In vivo study}

In vivo studies results are shown in Figure 6. Zaleplon $\mathrm{C}_{\max }$ showed $151 \mathrm{ng} / \mathrm{mL}$ and $30 \mathrm{ng} / \mathrm{mL}$ values after MEBG transdermal delivery and oral tablet (Sonata), respectively. $\mathrm{T}_{\max }$ showed $1.5 \mathrm{~h}$ and $11 \mathrm{val}-$ ues after MEBG delivery and Oral Xika tablet 

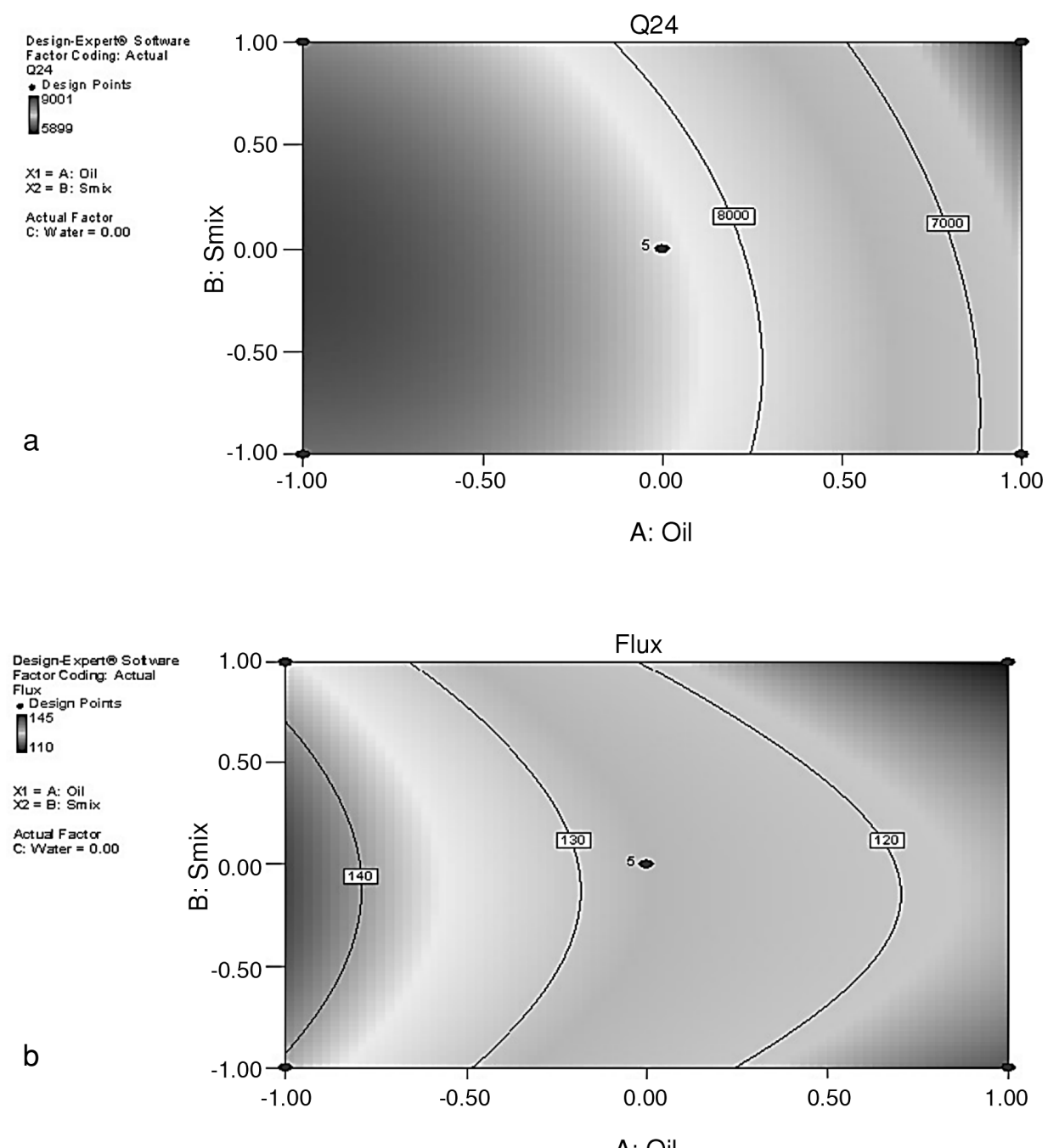

A: Oil

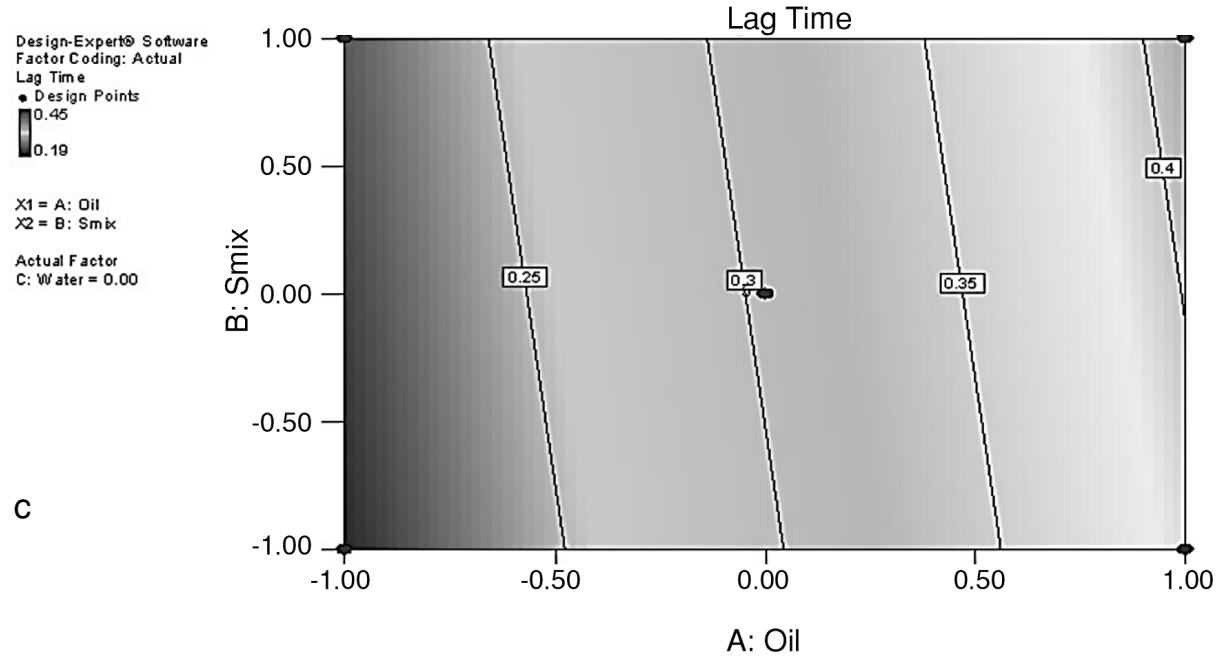

Figure 4. Contour plot showing effects (a) $\mathrm{Q}_{24}$ (b) Flux (c) Lag Time corresponding response surface plots (d-f) 

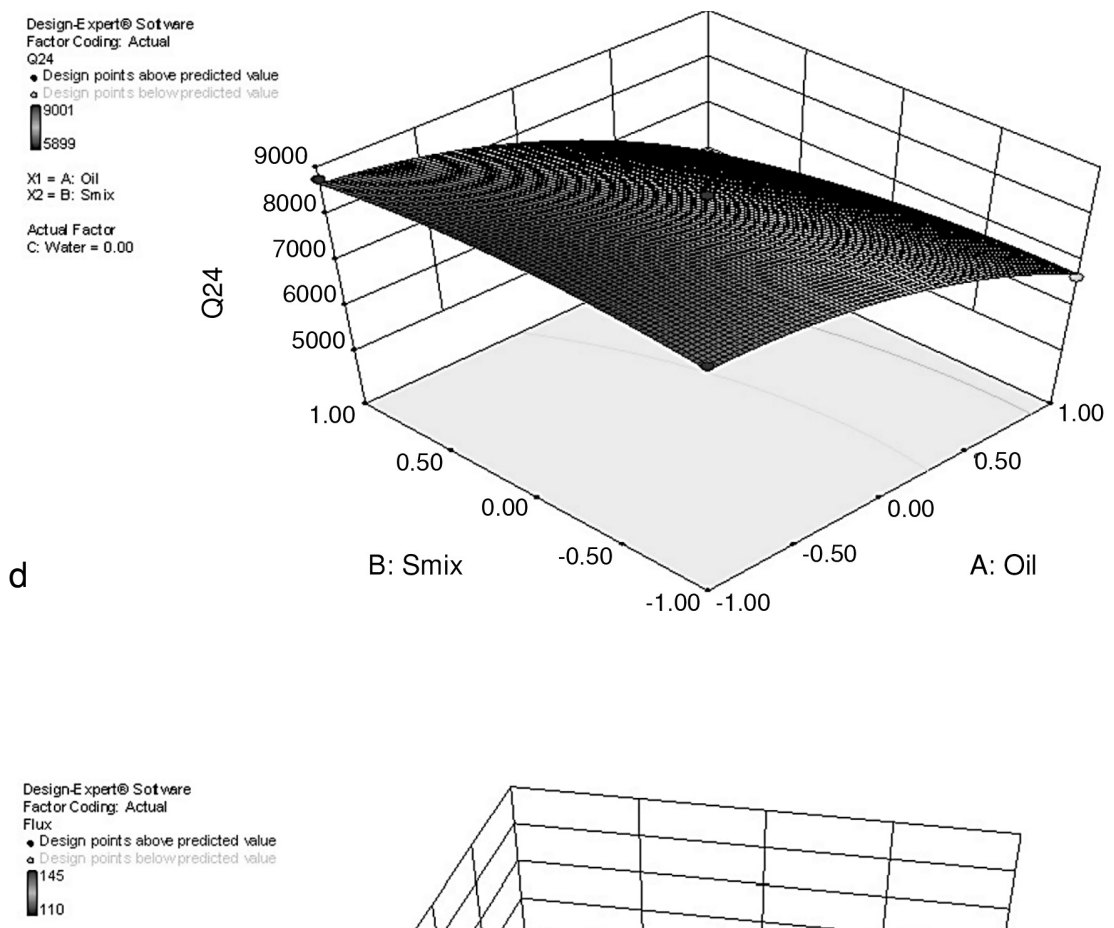

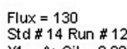

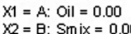

Actuaf Facta

e

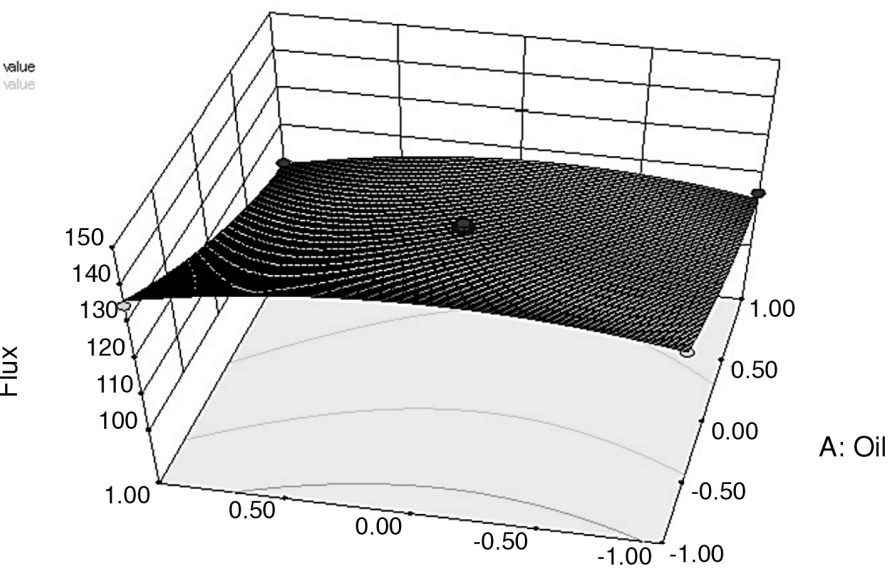

B: Smix

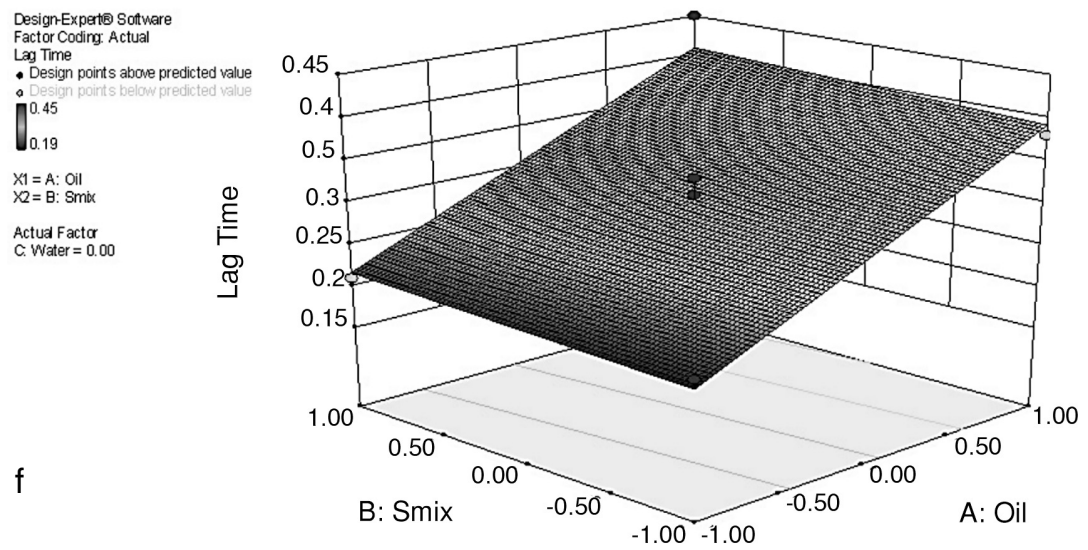

Figure 4. Continued 
respectively. $\mathrm{AUC}_{\text {total }}$ values were $3800 \mathrm{ng} . \mathrm{h} / \mathrm{mL}$ and 450 ng.h/mL, respectively, after MEBG delivery and tablet (oral Xika).

\section{DISCUSSION}

\section{Components of microemulsions}

The larger dermal flux was noticed primarily as large solubilizing microemulsion capability that concludes enhanced concentration gradient via rabbit skin. Solubility studies are performed to choose GRAS (generally regarded as safe) microemulsion components for high solubility, that acts a major role for drug permeation and bioavailability. Compatibility for individual microemulsion components is the main element with respect to microemulsion preparation (20). Castor oil was chosen as it shows skin safety, attractive fragrance, anti-oxidant and antiseptic characteristics. It exhibits higher solubility for Zaleplon and greatly miscible with other microemulsion components. Castor oil is monounsaturated chemically that is used to enhance permeation (21). Non-ionic surfactant was selected as optimal potential surfactants as it is non-toxic, bio-compatible, neutral and stable over varying $\mathrm{pH}$. It was chosen as it shows HLB value higher than 10 for synthesizing oil/ water microemulsion. Tween 80 was chosen as a non-ionic surfactant (HLB 15) as it performs greater solubility for Zaleplon and greater miscibility with other microemulsion components (22). Polyethylene 200 (PEG 200) was chosen as co-surfactant as it exhibits large miscibility with other microemulsion components. It allows interfacial film with suitable flexibility to undertake various curvatures, needed to prepare microemulsion over a broad concentration range and decrease the interfaces bending stress (23).

\section{Pseudoternaryphase diagrams}

Pseudoternary phase diagrams were selected to determine concentration ranges of chosen microemulsion components for the presence of the microemulsion region (13). Isotropic, low viscosity and clear area were depicted in the phase diagram using single phase translucent region for microemulsion (Figure 1). Remaining area in ternary diagrams on visual determination was multi-phase conventional and turbid emulsion. There was no observation for microemulsion nature conversion from oil/ water to water/ oil. Microemulsion region was narrowing on result to increase Smix weight ratios. It shows the microemulsion region reduced with enhancing and reducing surfactant and co-surfactant concentrations, respectively (24).

\section{Effects of MEBG}

Various concentration effects of carbomer 940 polymer upon optimized microemulsion $\mathrm{ME}_{1}$ viscosity was estimated via dispersing and swelling at $0.50 \%, 0.75 \%$ and $1.00 \%$ concentrations, individually to the aqueous phase. When TEA added to change $\mathrm{pH}$ for swelling of polymer gel bases, MEBG were prepared via mixing oil phase to various gel bases. Carbomer 940 gel base addition resulted in broad increase viscosity as microemulsion has little viscosity. MEBG viscosity having car-

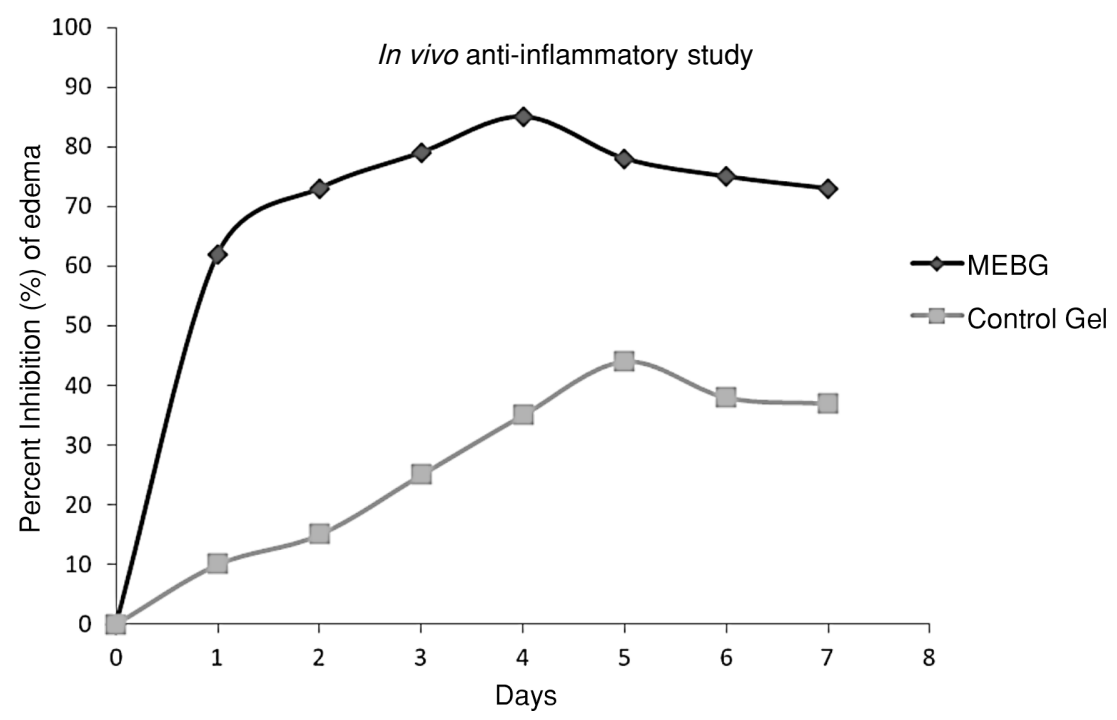

Figure 5. Anti-inflammatory activity of MEBG and control gel 
Table 4. Composition of checkpoint formulations, the predicted and experimental values of response variables, and percentage prediction error.

\begin{tabular}{|c|c|c|c|c|c|c|c|}
\hline No. & Oil & Smix & Water & $\begin{array}{l}\text { Response } \\
\text { variables }\end{array}$ & $\begin{array}{l}\text { Predicted } \\
\text { value }\end{array}$ & $\begin{array}{l}\text { Experimental } \\
\text { value }\end{array}$ & $\begin{array}{c}\text { Percentage } \\
\text { prediction error }\end{array}$ \\
\hline \multirow[t]{3}{*}{1} & -1 & 0 & +1 & $\mathrm{Y}_{1}$ & 6672 & 9001 & 0.21 \\
\hline & & & & $\mathrm{Y}_{2}$ & 174 & 145 & 1.36 \\
\hline & & & & $\mathrm{Y}_{3}$ & 0.22 & 0.19 & 9.52 \\
\hline \multirow[t]{3}{*}{2} & 0 & +1 & +1 & $\mathrm{Y}_{1}$ & 6475 & 7881 & 0.25 \\
\hline & & & & $\mathrm{Y}_{2}$ & 169 & 118 & 1.67 \\
\hline & & & & $\mathrm{Y}_{3}$ & 0.23 & 0.34 & 2.86 \\
\hline \multirow[t]{3}{*}{3} & 0 & +1 & -1 & $\mathrm{Y}_{1}$ & 6071 & 7945 & 0.70 \\
\hline & & & & $\mathrm{Y}_{2}$ & 161 & 120 & 0.83 \\
\hline & & & & $\mathrm{Y}_{3}$ & 0.25 & 0.34 & 2.86 \\
\hline \multirow[t]{3}{*}{4} & 0 & 0 & 0 & $\mathrm{Y}_{1}$ & 5841 & 8133 & 0.82 \\
\hline & & & & $\mathrm{Y}_{2}$ & 152 & 124 & 0.80 \\
\hline & & & & $\mathrm{Y}_{3}$ & 0.26 & 0.33 & 2.94 \\
\hline \multirow[t]{3}{*}{5} & -1 & -1 & 0 & $\mathrm{Y}_{1}$ & 5670 & 8830 & 0.79 \\
\hline & & & & $\mathrm{Y}_{2}$ & 151 & 139 & 1.42 \\
\hline & & & & $\mathrm{Y}_{3}$ & 0.27 & 0.21 & 4.55 \\
\hline \multirow[t]{3}{*}{6} & +1 & 0 & +1 & $\mathrm{Y}_{1}$ & 5481 & 7222 & 1.07 \\
\hline & & & & $\mathrm{Y}_{2}$ & 144 & 117 & 0.85 \\
\hline & & & & $\mathrm{Y}_{3}$ & 0.28 & 0.36 & 2.70 \\
\hline \multirow[t]{3}{*}{7} & +1 & +1 & 0 & $\mathrm{Y}_{1}$ & 5143 & 5899 & 0.02 \\
\hline & & & & $\mathrm{Y}_{2}$ & 138 & 110 & 1.79 \\
\hline & & & & $\mathrm{Y}_{3}$ & 0.28 & 0.45 & 2.17 \\
\hline \multirow[t]{3}{*}{8} & +1 & -1 & 0 & $\mathrm{Y}_{1}$ & 4837 & 6683 & 0.99 \\
\hline & & & & $\mathrm{Y}_{2}$ & 132 & 115 & 0.86 \\
\hline & & & & $\mathrm{Y}_{3}$ & 0.30 & 0.38 & 2.56 \\
\hline \multirow[t]{3}{*}{9} & -1 & 0 & -1 & $\mathrm{Y}_{1}$ & 4538 & 8950 & 0.56 \\
\hline & & & & $\mathrm{Y}_{2}$ & 121 & 142 & 0.70 \\
\hline & & & & $\mathrm{Y}_{3}$ & 0.31 & 0.20 & 4.76 \\
\hline \multirow[t]{3}{*}{10} & +1 & 0 & -1 & $\mathrm{Y}_{1}$ & 4005 & 6313 & 1.36 \\
\hline & & & & $\mathrm{Y}_{2}$ & 109 & 114 & 0.87 \\
\hline & & & & $\mathrm{Y}_{3}$ & 0.33 & 0.39 & 4.88 \\
\hline
\end{tabular}

bomer 940 at concentration $0.50 \%, 0.75 \%$ and $1.00 \%$ shows $60000,15000,16500 \mathrm{cP}$, respectively. MEBG at $0.5 \%$ exhibited relatively greater fluidity. Despite at $1 \%$ concentration caused higher gel viscosity, although Lapasin noticed appropriate $1 \%$ carbomer 940 (Lapasin et al., 2001). Gel at 0.75\% concentration exhibited suitable fluidity for application for transdermal delivery. Consequently, at $0.75 \%$ concentration carbomer 940 is optimum and suitable gel base for fabricating MEBG (13).
Physicochemical characteristics of microemulsions

$\mathrm{pH}$ reduced widely for all 17 microemulsions because the concentration of water consecutively enhanced. At higher concentration of water, organic acid ionization enhances, producing high solution protons and then reducing $\mathrm{pH}(25) . \mathrm{pH}$ is an optimal effective indicator for inspecting skin safety (26). Although microemulsion $\mathrm{pH}$ was within physiological range and skin safe that is insignificant. 
Although MEBG was synthesized using adjusted microemulsion $\mathrm{pH}$ that is completely safe and distinguished for transdermal applications to the skin (27).

The measured viscosity was enhanced at greater oil concentration. Enhancing water concentration was predicted to decrease viscosity and reducing surfactant and co-surfactant concentration, enhance interfacial tension for water and oil. There was increased viscosity as reducing interfacial area and enhancing internal domains size. Incorporating polyethylene glycol 200 (co-surfactant) caused in changing the flow to Newtonian. The viscosity was enhanced using $3: 1>2: 1>1: 1$ Smix ratio. Smix at $3: 1$ exhibited greater viscosity (23).

Viscosity is defined as a flow characteristic (28). Newtonian flow is designed for microemulsions. Microemulsion viscosity is dependent upon oil, surfactant, co-surfactant and water components (29). Microemulsion did not show adhere to the skin as it represents low viscosity. As viscosity enhanced via adding $\mathrm{ME}_{1}$ into gel base of carbomer 940 to synthesize sustain and therapeutically effective preparation for extended time period. Consequently, microemulsion and MEBG were the best vehicles and therapeutic dosage forms, respectively, for Zaleplon transdermal delivery.

Conductivity $(\sigma)$ is defined as a flow of free ions in microemulsion (30). Figure 1 exhibited an extensive range of low viscosity, isotropic and stable microemulsions when distinguishing with increasing concentration of water. It shows water influence on microemulsion conductivity. Because the concentration of water increased, so electrical conductivity also enhanced and reduced with reducing water concentration (31). Conductivity values exhibit the formed microemulsion is oil/water as it utilizes water continuous phase.

It is validated that a strong and powerful correlation is exists for microemulsion structure and its conductivity behavior. It is, therefore, a beneficial factor for estimating microemulsion characteristics. This modulation is explained via production of bicontinuous structures that is ultra-low interfacial tension. Greater than $1 \mu \mathrm{Scm}^{-1}$ conductivity values are the property of microemulsions bi-continuous type or solution whereas water existence in continuous pseudo-phase concluded for conductivity measurement (32). These dynamic optimal structures consisted of oil and water, pseudo domains which can sharply vary. Its values are poor as using oil for continuous phase and intense as employing continuous phase water.

Microemulsion refractive index exhibit little angle of scattering and its value enhanced with enhancing oil and surfactant concentration. It was also estimated that enlarged oil and surfactant concentrations conclude in enhanced droplet size as it represents a higher scattering angle and then refractive index enhances (27). Refractive index is employed for checking isotropic, clarity and microemulsion transparency with scattering light principle which requires the application of an incident beam of radiation. Subsequently, it assists to

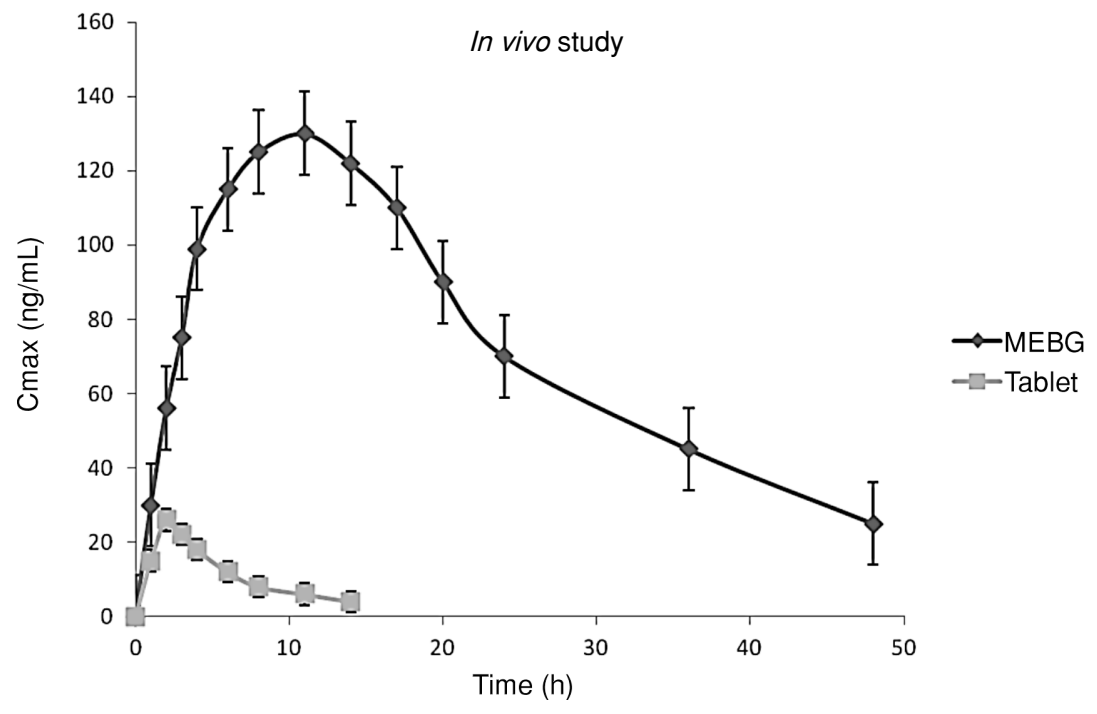

Figure 6. Mean serum profiles of Zaleplon in rabbits, after delivery of MEBG and Oral Sonata tablet 
find intensity and scattered beam angle. Large and little microemulsion droplets have higher and little scattering angle, respectively (33).

Droplet size was little, deflocculated and in range of microemulsion. All poly-dispersity index values were little than 0.5 that explains homogeneous nature and droplets narrow size distribution (13). Zeta potential value depicted microemulsion stability bearing non-ionic surfactants and zeta potential independent. Little droplet size produces higher stability for flocculation, sedimentation and coalescence (34). Poly-dispersity index values were near to one showing droplet size within significant uncertainty. As droplets are little then they exhibit negative zeta potential and property of deflocculation in uniform distribution (35).

Droplets were nearly spherical in shape bearing smooth surface and distribute uniformly. No aggregation or adhesion for microemulsion droplets of microemulsion because they are uniformly distributed and deflocculated into the system (Figure 2) (36). AFM is an essential indicator for distinguishing the topographical characteristics of submersed droplets into the liquid with construing shape, microemulsion size and morphology. It employed to find microemulsion microstructure (37). The major benefit for performing AFM is the direct estimation of 3D display and volume.

\section{In vitro skin permeation experiments}

The variable effects of changing $\mathrm{Q}_{24}$, flux and lag time demonstrating the Zaleplon permeation parameters from microemulsions were widely affected using a composition of microemulsions. Oil was chosen because it increases permeation by varying nature of solvent for stratum corneum that in turn enhances drug partition across viable tissues. It is permeated through the skin after transdermal delivery and extensive concentrations are present into the epidermis. It also improves drug diffusion via membrane. Between steady state permeation using penetration enhancer, lag time is usually reduced for permeation, exhibiting enhance in diffusion of the drug via membrane (38). Surfactant was chosen as it enhances permeation using lipid stratum corneum inducing fluidization and eventually solubilizing and lipid extraction components. Its interaction and binding with keratin filaments cause disruption of corneocyte that in turn enhance permeation (39). The co-surfactants specifically short-chain alcohols are employed to enhance the flux by varying relative system hydrophilicity and hydrophobicity (40). The phenomenon estimated behind is further fluidity for interfacial film due to permeation of surfactant monolayer and then crystalline phases disruption produced as a result of surfactant film rigidity. As permeation enhancer and solubilizer, polyethylene glycol 200 (PEG 200) not only enhances the drug solubility into the solvents but also varies the histology and anatomy of bio-membrane owing lipid extraction and enhances the drug permeability. Concentration of water enhanced permeation release of the stratum corneum that conclude in creation and widening of keratin layer channels and after that lipid bilayer distortion (41). PBS of $\mathrm{pH} 7.4$ was suitable for performing in vitro permeability release studies. It is important because it shows near neutral $\mathrm{pH}$ of Zaleplon transdermal delivery via Rabbit skin and could assist for drug diffusion through bi-layer membrane of lipid (18). These results exhibit the microemulsion potent enhancement effect for achieving transdermal delivery. It was observed the concentration of Zaleplon permeated and reduced in flux with increased medium to high-level concentration of the surfactant. Results showed a decrease in Zaleplon thermodynamic activity of microemulsion for high surfactant concentrations. Thermodynamic activity plays a vital role in permeation release and dermal drug permeation across the skin. The drug can be diffused via surfactant flexible interfacial film among the phases; thermodynamic enhances drug diffusion and partitioning through stratum corneum. Despite drug permeation was reduced by Smix high levels, this was due to Zaleplon attraction of surfactant and oil phase. Lag time reduced with high Zaleplon concentration permeated during $24 \mathrm{~h}$. Microemulsion droplets optimum chance was adherence to skin and bioactive particle delivered in a more patterned controlled manner. Large extensive surface area was present for optimum permeation through skin owing to very little microemulsion droplet size and higher drug concentration via upper skin layers resulted in a higher drug concentration gradient that is an ideal optimal transdermal delivery driving force (42). A decrease in the rate of drug permeation for enhanced microemulsion viscosity. Diffusion is a step that is rate-determining via double layer of microemulsion. Viscosity plays a vital role in drug controlling rate and drug extent into the receptor compartment. Results showing Zaleplon $\mathrm{ME}_{1}$ has enhanced drug permeation via skin. Higher concentration of surfactants enhanced permeation rate besides from enhancing permeation of castor oil. Briefly, MEBG exhibited sustained Zaleplon permeation than $\mathrm{ME}_{1}$ (43-44). This phenomenon could be elucidated for delayed release effect for polymer matrix, primarily as to enhance viscosity creating using Carbomer gelation (13). 
Peltola has studied carbomer 940 effects on permeation of estradiol. The carbomer 940 addition in microemulsion decreased the estradiol permeation and it suggested for increasing viscosity and converting from microemulsion to a lamellar structure or highly ordered structure (45).

\section{Fitting data to the model}

All 17 microemulsions exhibited significantly greater values of $\mathrm{Q}_{24}$ and flux. DES was employed concurrently for fitting responses for all microemulsions prepared using $1^{\text {st }}, 2^{\text {nd }}$ and quadratic models. A quadratic model was estimated as the best fit model. $\%$ coefficient of variation (\% CV), $\mathrm{R}^{2}$ comparative values and standard deviation (SD) were created of every response using regression equations. Positive and negative values estimated the positive effect that favors optimization and also inverse interaction for variable and response surface plots, respectively. It is evident that $\mathrm{X}_{3}$ exhibited a positive response on $\mathrm{Y}_{1}$ and $Y_{2}$ response. $X_{2}$ exhibited a positive optimum effect on $\mathrm{Y}_{3}$ response. Independent variables effects were measured and optimum microemulsions were chosen using depicting 3 dimensional response (Figure 4d-f) (14).

\section{Data analysis}

Optimum preparations of $\mathrm{ME}_{1}, \mathrm{ME}_{6}, \mathrm{ME}_{11}$, $\mathrm{ME}_{17}$ exhibited the greater values of $\mathrm{Q}_{24}\left(\mathrm{Y}_{1}\right)$ and $\mathrm{Y}_{2}$ (flux). Both observed and the predicted values for $\mathrm{Y}_{1}, \mathrm{Y}_{2}$ and $\mathrm{Y}_{3}$ are shown in Table 4 with respect to percent error and responses residual for formulations. Dependent variables (acquired using 3 independent variables) were exposed to multiple regressions for generating polynomial equations using the quadratic model. Correlation coefficient $\mathrm{R}^{2}$ of equation (Eq 4) was 0.987 representing a good fit. The predicted R-Square (0.9892) was found to be in reasonable agreement with adjusted $\mathrm{R}$ square value (0.9754) which exhibit a difference of less than 0.2. Adequate Precision estimated to be signal to noise ratio. A ratio higher than 4 was required. The software produces a ratio of 28.5 representing an optimal signal. This model was employed for navigating design space. Significant variation was observed for various microemulsions which assorted from 5899 to $9001 \mu \mathrm{g}$ of $\mathrm{ME}_{8}$ and $\mathrm{ME}_{1}$, respectively. Results distinctly exhibited value of $Y_{1}$ significantly affect using factors chosen for the study. The major effects for $\mathrm{X}_{1}, \mathrm{X}_{2}$ and $\mathrm{X}_{3}$ exhibited an average result of factors which changes at a time from low to high optimum level. The $\mathrm{X}_{1} \mathrm{X}_{2}, \mathrm{X}_{1} \mathrm{X}_{3}, \mathrm{X}_{2} \mathrm{X}_{3}, \mathrm{X}_{1}{ }^{2}, \mathrm{X}_{2}{ }^{2}$ and $\mathrm{X}_{3}{ }^{2}$ interaction terms represented how $\mathrm{Y}_{1}$ variated during two factors modified concurrently. The three independent variables showed unfavorable interaction with negative coefficient on $\mathrm{Y}_{1}$. Positive coefficient exhibited the optimum effect on $Y_{1}$ for changing for two variables. The lowest coefficient was 233 for $\mathrm{X}_{2}$ using three independent variables which represented the variable was found to be insignificant for $\mathrm{Y}_{1}$ prediction. $\mathrm{R}^{2}$ value was 0.9931 of equation (Eq 5) representing a good fit. The predicted $\mathrm{R}$ Square 0.8423 was found to be in close agreement with adjusted R-Square 0.9892 with the optimum difference of less than 0.2. Adequate Precision estimated the signal to noise ratio. A ratio higher than 4 was required. Software created a ratio of 28.5 that showed an adequate signal. This model was employed for navigating design space. $\mathrm{Y}_{2}$ were greater for $\mathrm{ME}_{1}, \mathrm{ME}_{6}, \mathrm{ME}_{11}$, and $\mathrm{ME}_{17}$. Flux enhanced between medium to low levels of $\mathrm{X}_{1}$, low to medium levels of $X_{2}$ and low to high levels of $X_{3}$. $\mathrm{Y}_{2}$ of all 17 runs show significant variation ranging between $135-145 \mu \mathrm{g} / \mathrm{cm}^{2} / \mathrm{h}$. The terms $X_{1} X_{2}, X_{1} X_{3}$, $\mathrm{X}_{2} \mathrm{X}_{3}, \mathrm{X}_{1}{ }^{2}, \mathrm{X}_{2}{ }^{2}$ and $\mathrm{X}_{3}{ }^{2}$ showed $\mathrm{Y}_{2}$ changed as 2 factors varied at once. Positive coefficient represented the favorable positive effect on the interaction of two variables. Lowest coefficient value -28 was for variable $X_{1}$ in three independent variables which represented the factor was found to be insignificant for flux prediction. $\mathrm{R}^{2}$ value of equation (Eq 6) was 0.993. Predicted R-Square 0.9268 was found to be in reasonable agreement with adjusted R-Square (0.9100) that is variation was less than 0.2. Adequate Precision estimated signal to noise ratio. A ratio higher than 4 was required. DES was employed to create a ratio of 23.7 which represent the adequate optimal signal. This model was employed for navigating design space. Lag time was less for $\mathrm{ME}_{1}, \mathrm{ME}_{6}, \mathrm{ME}_{11}, \mathrm{ME}_{17}$, representing an insignificant difference $(\mathrm{p}>0.05)$. Lag time enhanced between low to high levels for factors $X_{1}$, $\mathrm{X}_{2}$ and medium to low of variables $\mathrm{X}_{3} . \mathrm{Y}_{3}$ was enhanced with aggregation of drug for stratum corneum layers. $\mathrm{Y}_{3}$ also enhanced for solubilizing and drug affinity for variable $X_{2}$. Interaction terms $X_{1} X_{2}$, $\mathrm{X}_{1} \mathrm{X}_{3}, \mathrm{X}_{2} \mathrm{X}_{3}, \mathrm{X}_{1}^{2}, \mathrm{X}_{2}^{2}$ and $\mathrm{X}_{3}^{2}$ showed $\mathrm{Y}_{3}$ varied as 2 factors varied simultaneously. Positive coefficient represented a favorable optimum effect on $\mathrm{Y}_{3}$ of interaction for two factors. Lowest coefficient 5 for three independent variables was of level $\mathrm{X}_{3}$, indicating variable was found to be insignificant for predicting $Y_{3}(14)$.

\section{Contour plots and response surface analysis}

Interaction of variables on response surface plots was estimated using contour and response surface plots (Figure 4). At a time, the influences of both factors with phase plots were measured using 
responses. In figures, the $3^{\text {rd }}$ factor was at a constant level. All parameters were found to be non-linear for three variables. Despite the $X_{2}$ with $X_{1}$ and $X_{3}$ showed almost linear connection by forming nearly straight graphical lines towards medium level of Smix. When concentration of $\mathrm{X}_{2}$ reached higher level it consequences in curvilinear or nonlinear relationship. $\mathrm{X}_{2}$ and $\mathrm{X}_{3}$ factors exhibited almost curvilinear relationship for these variables even more precisely using two variables all levels on $\mathrm{Y}_{2}$ response. At oil constant concentration, values of $Y_{1}$ and $Y_{2}$ increased with concentration enhancement of water or Smix (up to medium level) (18).

\section{Optimization}

Optimum preparations were chosen using constraints as $\mathrm{Y}_{1}(5899=\mathrm{Y}=9001), \mathrm{Y}_{2}(110=\mathrm{Y}=145)$ and $\mathrm{Y}_{3}(0.19=\mathrm{Y}=0.45)$. Optimum microemulsions of maximum optimum requisite were accomplished using criteria maximum $\mathrm{Y}_{1}$ and $\mathrm{Y}_{2}$ and minimum $\mathrm{Y}_{3}$ value. It represented the percentage composition of oil $5 \%$, Smix $45 \%$ and water $47 \%$ upon exchanging of many response variables. It was a comprehensive optimum evaluation of exhaustive and feasibility grid search.

\section{Validation of response surface plots}

Dependent variables concentrations were employed and ten checkpoints were obtained using RSM. Experimental and predicted responses values for these preparations are stated in Table 4. In vitro permeation studies were subjected to validate the optimal parameters and predicted response. It was optimum that predicted errors are found to be less than $5 \%$. It was estimated that the responses are found to be in close agreement with that of predicted values. Percentage prediction error was employed for validity of general equations. This result explained RSM model application for a domain. The linear correlation plots created for predicted and experimental values and employed for explanation of $R^{2}$ high values, representing the goodness of fit (14).

\section{Thermodynamic stability study}

The point of stability testing is to give proof on how the medicinal product contents active pharmaceutical fixing (API) changes regarding time affected by various environmental variables including temperature, humidity and light build up a retest period for API or shelf life of therapeutic item and affirmed storage conditions. Stability testing is performed using ICH-Guideline Q1A (46). Thermodynamic stability studies estimated the stability of the optimized formulations. A microemulsion is found to be stable when it doesn't exhibit phase separation does, change in concentration and organoleptic characteristics (47). In current work, visual examination exhibited the optimized formulations as stable after performing freeze-thaw cycles and centrifugation. The results exhibited the Zaleplon was found stable throughout the study. The results exhibit the insignificant difference $(p>0.05)$ with initial permeation in permeation showing both formulations were found to be stable. The formulations were stable and no drug concentration change found, phase separation occurred and change in color was noticed because it is isotropic, thermodynamically stable and clear (48).

\section{Skin irritation study}

Nevertheless, Generally Regarded as Safe (GRAS) components were employed for preparation of microemulsions. For instance, a big concentration of surfactants resulted in skin irritation. Usually, the skin irritation test was performed to check suitable concentrations of components employed for microemulsion preparation. This test was conducted to find out the optimized microemulsion localized reaction on the skin (49). Skin erythema index represents the optimized formulations skin irritation (50). In the current study, insignificant difference values were estimated before and after MEBG application for skin erythema. No irritation was found on the skin (51).

\section{Anti-inflammatory study}

Inflammation was cured using MEBG and control gel. Edema was little comparatively than control gel which showed Zaleplon permeation through skin showed anti-inflammatory activity. For differentiating anti-inflammatory activity, the percent inhibition of edema was showing in Figure 4. Optimum and effective efficacy was observed for MEBG than control gel complete study which revealed incorporation of Zaleplon into MEBG enhances the antiinflammatory activity (52).

\section{Pharmacokinetics}

Results showed the Zaleplon was released and permeated continuously from MEBG as compared to oral Xika rapid tablet. The values of AUC, $T_{\mathrm{Max}}$ and $C_{\text {Max }}$ were distinguished. Usually, $\mathrm{AUC}_{\text {total }}$ mean value was higher for MEBG than the oral tablet. This showed optimum improved bioavailability of Zaleplon MEBG. It was because of the hindrance of first pass metabolism across the transdermal route. $T_{\text {Max }}$ values were higher and significant $(\mathrm{p}<0.05)$ for transdermal delivery The values of $T_{\text {Max }}$ were found out greater 
and significant $(\mathrm{p}<0.05)$ in all the Rabbits for transdermal delivery than oral delivery. This was because of the barrier capability of stratum corneum that delayed and sustained the permeation and release of Zaleplon MEBG than oral delivery. Therefore MEBG was an effective optimum therapy for the treatment of inflammation and rheumatoid arthritis $(14,50)$.

\section{CONCLUSION}

Zaleplon solubility was enhanced using microemulsion components as solubilizers and these components extracted the lipid from bio-membrane which in turn enhanced the permeability through the skin of rabbit. Independent variables were optimized using BBD for estimating dependent variables which suggested the best fit to the quadratic model. Adhesion of microemulsion $\left(\mathrm{ME}_{1}\right)$ was enhanced by making its MEBG which extend its retention time upon the skin. The results demonstrated the transdermal suitability of MEBG which did not cause erythema and non-irritating to the Rabbit skin. Odema percent inhibition with MEBG was significant as compared to control gel when the antiinflammatory study was performed. In vivo results revealed improved optimum permeation of Zaleplon MEBG as the comparison with an oral tablet. This system further can be assessed for (BCS) II drugs.

\section{Conflict of interest} this work.

The authors report no conflicts of interest in

\section{REFERENCES}

1. Dooley M., Plosker G.L.: Drugs 60, 413 (2000).

2. Dämgen K., Lüddens H.: Neurosci. Res. Comm. 25, 139 (1999).

3. Kenneth E.T., Danny D.S.: in Goodman \& Gilman's The Pharmacological Basis of Therapeutic $10^{\text {th }}$ ed., Hardman J.G., Limbard L.E. Eds., McGraw-Hill, New York 2001.

4. Drover D.R.: Clin. Pharmacokinet. 43, 227 (2004).

5. Hörter D., Dressman J.: Adv. Drug Deliv. Rev. 25, 3 (1997).

6. Drover D., Lemmens H., Naidu S., Cevallos W., Darwish M., Stanski D.: Clin. Ther. 22, 1443 (2000).

7. Naeem M., Rahman NU., Khan JA., Sehti A., Nawaz Z.: Lat. Am. J. Pharm. 32, 1196 (2013).

8. Mizushima Y., Hamano T., Yokoyama K.: J. Pharm. Pharmacol. 34, 49 (1982).
9. Aggarwal N., Goindi S., Khurana R.: Colloid. Surf. B 105, 158 (2013).

10. Cevc G., Vierl U.: J. Control. Release 141, 277 (2010).

11. Marti-Mestres G., Nielloud F.: J. Disper. Sci. Technol. 23, 419 (2002).

12. Khuri A.I., Mukhopadhyay S.: Wiley Interdiscip. Reviews: Comput. Stat. 2, 128 (2010).

13. Chen H., Mou D., Du D., Chang X., Zhu D. et al.: Int. J. Pharm. 341, 78 (2007).

14. Gannu R., Rao Y.M.: J. Disper. Sci. Technol. 33, 223 (2012).

15. Idrees M., Rahman N., Ahmad S., Ali M., Ahmad I.: DARU 19, 433 (2011).

16. Shukla J.B., Patel S.J.: J. Pharm. Pharm. Sci. 2, 143 (2010).

17. Bayrak Y., Iscan M.: J. Disper. Sci. Technol. 26, 75 (2005).

18. Al-Suwayeh S.A., Taha E.I., Al-Qahtani F.M., Ahmed M.O., Badran M.M.: Sci. World J. 2014, pages 9 (2014).

19. Reversed-Phase Liquid Chromatographic Determination of Zaleplon in Human Plasma and its Pharmacokinetic Application.

20. Bayrak Y., Iscan M.: Colloids Surf. A 268, 99 (2005).

21. Lee J.M., Park K.M., Lim S.J., Lee M.K., Kim C.K.: J. Pharm. Pharmacol. 54, 43 (2002).

22. Gannu R., Palem C.R., Yamsani V.V., Yamsani S.K., Yamsani M.R.: Int. J. Pharm, 388, 231 (2010).

23. Hosny K.M., Banjar Z.M.: Expert Opin. Drug Deliv. 10, 1033 (2013).

24. Huang C.-C., Hohn K.L.: J. Phys. Chem. B.114, 2685 (2010).

25. Spernath A., Aserin A., Garti N.: J. Colloid Interf. 299, 900 (2006).

26. Hathout R.M., Woodman T.J., Mansour S., Mortada N.D., Geneidi A.S., Guy R.H.: Eur. J. Pharm. Sci. 40, 88 (2010).

27. Chen H., Chang X., Weng T., Zhao X., Gao Z. et al.: Control. Release 98, 427 (2004).

28. Jadhav K., Ambade K., Jadhav S., Gambhire M., Kurmi S., Kadam V.: Curr. Drug Deliv. 5, 32 (2008).

29. Yuan J.S., Ansari M., Samaan M., Acosta E.J.: Int. J. Pharm. 349, 130 (2008).

30. Talegaonkar S., Azeem A., Ahmad F.J., Khar R.K., Pathan S.A., Khan Z.I.: Recent Pat. Drug Deliv. Formul. 2, 238 (2008).

31. Fanun M.: J. Mol. Liq. 139, 14 (2008).

32. Graf A., Ablinger E., Peters S., Zimmer A., Hook S., Rades T.: Int. J. Pharm. 350, 351 (2008). 
33. Acharya D.P, Hartley P.G.: Curr. Opin. Colloid Interface Sci. 17, 274 (2012).

34. Cho Y.H., Kim S., Bae E., Mok C., Park J.: J. Food Sci. 73, E115 (2008).

35. Qu D., He J., Liu C., Zhou J., Chen Y.: Int. J. Nanomedicine 9, 109 (2014).

36. Fanun M.: J. Disper. Sci. Technol. 30, 115 (2009).

37. Fanun M., Makharza S., Sowwan M.: J. Disper. Sci. Technol. 31, 501 (2010).

38. Williams A.C., Barry B.W.: Adv. Drug Deliv. Rev. 64, 128 (2012).

39. Pandey A., Mittal A., Chauhan N., Alam S.: J. Mol. Pharm. Org. Process Res. 2, 2 (2014).

40. Patel M.R., Patel R.B., Parikh J.R., Solanki A.B., Patel B.G.: AAPS PharmSciTech. 10, 917 (2009).

41. Azeem A., Khan Z.I., Aqil M., Ahmad F.J., Khar R.K., Talegaonkar S.: Drug Dev. Ind. Pharm. 35, 525 (2009).

42. Sahoo S., Pani N.R., Sahoo S.K.: Colloid. Surface. B 120, 193 (2014).
43. Chen H., Chang X., Du D., Li J., Xu H., Yang X.: Int. J. Pharm. 315, 52 (2006).

44. Jana S., Manna S., Nayak A.K., Sen K.K., Basu S.K.: Colloid. Surface. B 114, 36 (2014).

45. Peltola S., Saarinen-Savolainen P., Kiesvaara J., Suhonen T., Urtti A.: Int. J. Pharm. 254, 99 (2003).

46. Principles D S Practices Carstensen T., Rhodes C.T.: Eds. Marcel Dekker. New York 2000.

47. Kogan A., Garti N.: Adv. Colloid Interface Sci. 123, 369 (2006).

48. Narang A.S., Delmarre D., Gao D.: Int. J. Pharm. 345, 9 (2007).

49. Soliman S.M., Malak N.A., El-Gazayerly O.N., Rehim A.A.: Drug Discov. Ther. 4, 459 (2010).

50. Gannu R., Palem C.R., Yamsani V.V., Yamsani S.K., Yamsani M.R.: Int. J. Pharm.388, 231 (2010).

51. Kantarcı G., Özgüney I., Karasulu H.Y., Arzık S., Güneri T.: AAPS PharmSciTech. 8, 75 (2007).

52. Lee I.O., Crosby G.: J. Korean Med. Sci.14, 34 (1999).

Received: 1.12.2018 